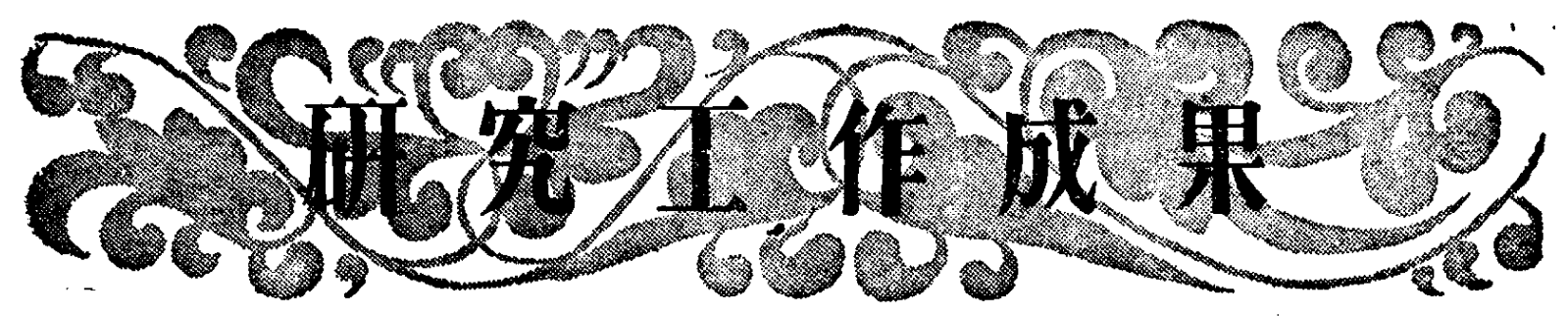

\title{
海帶的莘殖與存在的問題
}

曾呈奎点超元

（中國科等院海洋生物研究室）

海帶含有大量的碘、䥄、琢、維生素及其他 人體上所需要的物質(1)。千百年前, 遠在磑被化

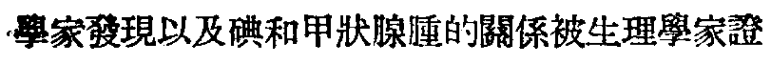
明以前，我國的勞動人民通過了多年的實践，就 已經知道海藻類食品, 特别是海韧, 在預防和醫 療甲狀腺腫上的價值。我國古代樂用植物書籍上 就記载了很多關於造類的知被。但是抗戰以前我 國人民消費的數千萬厅海帶都是從日本進口的。

海帶原產於日本、朝鮮與蘇聯遠東區沿海發 源於白令海及鄂篗淡克海的寒流流域, 移種於我 國踓然巳有二十多年的歴史, 然而由於養殖上存 在着許多困難, 一直停留在小規模的試 驗階段 、中。(2) 解放以後, 由於我人民政府的重視, 迅速

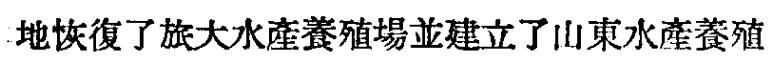

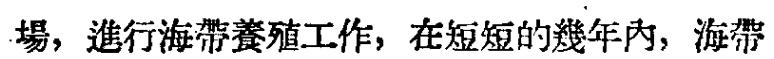
的養殖已經由小規模的試驗轉入企業性的階段。

踓然目前的量量還很少, 離開覃衆的要求還很 遠, 但是由於人民政府的正確領導和養殖業工作 同志的努力，已經堡定了這個新事業的基礎。

但是, 不能否認, 海滯食殖業還很幼稚, 還 存在着許多問題需要解决。海藻的䓹殖, 特別是 海帶的㵚殖, 如能成功地提高到現代譨業科學的 . 水平, 還就意味着人類在同大自然的丽学中獲得 了一個新的勝利, 在征服海洋的過程中又苟進了 一大步; 在經渓意義上, 我國沿海海灣無數萬的

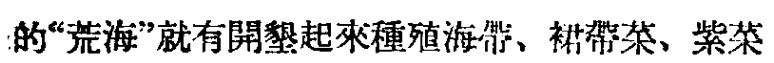
以及其他人民所需要的食品與工業原料的可能。 因此, 我們特向全國科學界介紹一下目前我國在
海帶飬殖業上所應用的方法和存在的問題，以引 起有關同志們的注意。

\section{一 海带的羕殖方法}

海帶是由單細胞的孢子來繁殖的。狍子的楎 造非常簡單, 没有抵抗惡少環境的能力, 一離海 水就會乾死; 因此, 必須在它們大量放散出來的 時候, 立刻用種種方法創造條件, 譲它們有合適 的機會順利地附着在一定的基居上。

藻類生活在海水襄, 其中水份、氧氣和二氧 化碳是很充足的, 至於温度與光贸, 如在一定的 季節和一定的深度種植, 也可以浾足植物的要 求, 但無機飬分, 例如氮 (确酸監) 和磷 (磷酸

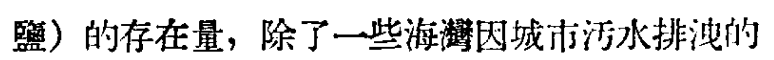

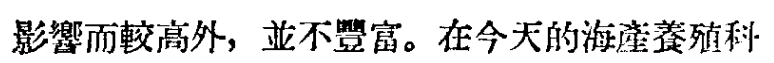
學技術的條作下，我們還不能够像改造土境那㩐 去改造海洋, 因此現在海藻食殖比較成功的只限 於某些所謂優良海區。近轹年來, 我國答動人民 已經創造了一些良好的海州食殖力法, 這些方法

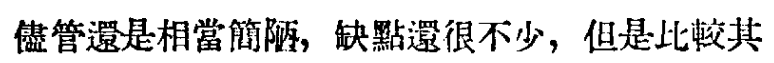
他海藻的養殖, 可以說是相當科學化的了。

海带的食殖可以分篇三個階段:

* 㞄篇交章是根㨜 1953 年的㗄料而舄的。我們

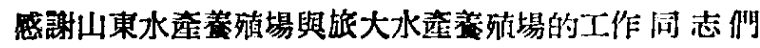
供給我們許多有關的資料，並提供了許多筫貴的意見，

(1) 看中央衛生研究院營盖學系糄著: “食物成 分表”，險歌印書館出版。

〔2〕曾呈奎: 海帶和海底森林, 生物算通報, 19 53 ( 9 ), 320-325。 


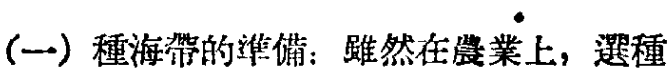

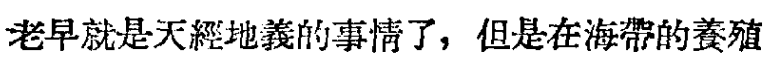

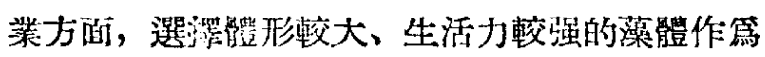
秦育下一代的種海㳣還是近年內的事情。在山束 沿岸，夏丈的游酘水湿到達 $27^{\circ} \mathrm{C}$ 以上, 因此, 種 海滞的渡夏是一個重要的任務, 否則過了夏天,

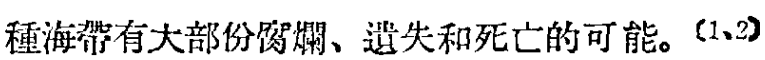

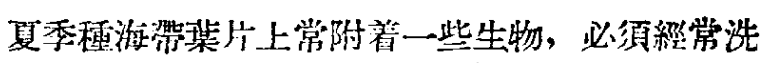
除, 否則會影響到呢子雯的形成。

（二）生長基庴的選摆：天然的生長基庴主 要是海底的岩石和石塊, 在這些坚層上的海帶的 生長是不易控制的。人工的生長基屏一般都是應

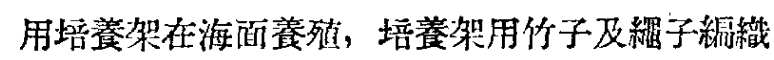
而成，架子兩端分别用長繩聯於鐵鎑或石塊以便 固定於海底, 竹架則任其漂浮水面, 所以也可以 叫做“浮架”。造種方法在操作上較篇輕便, 而且 收效也較大, 人工能够控制成分也較多。

（三）繁殖與䒅青：已經有了種海帶，並且 也已經選摆了生長的基展, 進一步的工作就是海 滞的繁殖與秦育。

(1) 自然繁殖法:

在自然的情况下, 海帶孢子菨成熟後, 就在 海水中陸續放散孢子，放散門間有一個多月。孢 子一䠊開母體, 立刻在海水敦尋宽它們所需要的 生長基層; 如果在一定的時間內 (本常只一、二 天）份不能找到基首，它們就會死亡; 即使找到 了基展, 但基展的位置及環境不一定能適合於孢 于的萌發與生長。因此, 在自然的情况下, 絕大 部份的孢子没有機會可以完成它們繁殖個體的使 命。在這裹, 如果㞦以人力的干涉, 將海帶孢子 體安頨在有很多的岩石而且深度也很合適的地 方, 那蘑, 成熟的時候, 孢子一放散就有地方可 以附着, 萌發, 生長了。

過去, 各地養殖場篔出過下列网種方法: （1）將海帶綁在石塊上, 然後飬育於適當的海 底 (綁纱增殖法);（2）將養育在能子上面的海

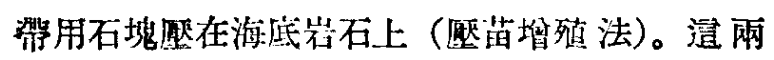
種方法都需要潛水員在海底進行工作, 藉以掂大 海橆在海底生長的面積, 但方法粗”积而且並不能 保證孢子一定有附着的機會, 質践登明, 應用選 種方法作篇繁殖海帶的結果都不很好。

（2）人工繁殖法:
通方法的基本特點就是利用人工方法刺激把 子的放散, 使我們能够在一定的短時間內收集大 量的孢子。人工繁殖法的步臂如下:

一人人工刺激: 一般是餫用乾燥法, 就是選 擇具有成熱孢子裂的海帶，從海水裹取出，放置 於陰暗而温度較低的地方。制激的時間從幾小時 到一、二天不等, 只要不過份地乾燥, 藻體不致 乾死, 就可以達到刺激的目的。在刺激的過程 中, 時常滴海水於小部份孢子装蔁上, 把水吸至 玻片, 在顯微鏡下检查孢子的放出量; 到了孢子 大量放出時，就可以進行下一步骤。

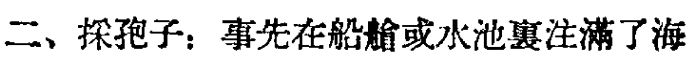
水, 然後將準備篇䓹育海梁用的生長基居（石 墔、樫子或竹片）放在水中，最後把把已經刺激 過的海帶放到水裹。海帶暴露在空氣中一定的時 間後, 孢子唼就失掉了一部分的水份, 因润增加 了它们滲透歷力, 再放進海水的時候, 阤子臸因 突然吸收大量的水份而裂閏; 因此, 在一等约短 時間內，很多的游動孢子就放散出桃。船秢或水 池裹的海水並不流動而且也很少, 因此, 綛大多 數的孢子都能够有附着在我們替它們淮借好的基 居上的機會。有孢子附着的生長基展就可以放在 海面或海底進行海带食育的工作。

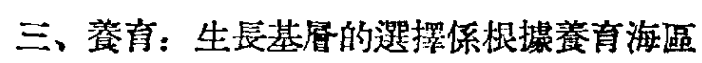
的情况而决定。風浪較大的海區不遮於浮噪式的 秦殖, 可以利用石塊作第基啳。探孢子後, 要在 短時間內將石塊投在所選摆的海诋, 然後遗派細 水員下海整理, 否則, 如果這些石塊被投在不遁 當的地點, 或者互相重嚳, 就會影響到海洮的生 長與弦育，失去了投石增產的意義了。這種增產 方法可以叫做 “採孢子投石法”（山束稃第“跑”韭 投石”，適用於還没有生長海帶的海底的食殖。

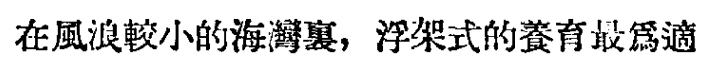
宜。旅大地區自然條件較篇優越, 海采的自然繁 殖和生長已經有了一定的基礎, 海帶的咅育力j法 亦可以簡化。將乾燥刺激後的海帶孢子體掛在浮 架上, 孢子就會自然放散在架子上, 而在同一地 方長成篇大型海帶, 没有分第有渵與培䓹㒳階段

(1)大㯕洋四郎: 山東沿崖海帶（昆布）羕殖 研討, 華東水蕉, $1952(11-12), 49-56$ 。

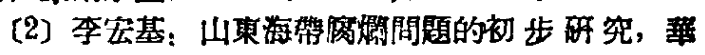
東水变， $1952(11-12) ， 57-66$ 。 
的必要。旅大䓹殖梤 1952 年秋用逜方法作了試 驗, 成精很好, 因此 1953 年秋季探孢子時就大

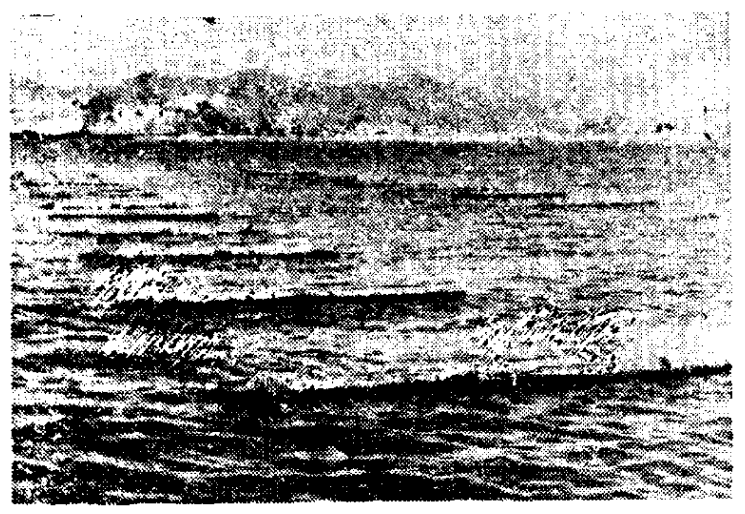

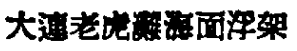

\section{量應用造種浮架。}

青島和其他山東䖭殖區自然佟件咬苃, 因此 所用方法較篇複椎, 在探阤子後, 得分第有苗和

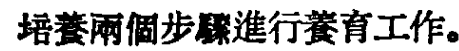

\section{二 海带的收婊}

（一）收磪期: 到了百季, 海帶一般有 2 -3 米長, 25 厘米筧, 少数有 $5-6$ 米長, 薘到了商 品標蕉, 可以進行收变工作. 收瓁時間各地不同。 收秷時間的裳握和產品的品質有很大的關係, 因 編收割如太早, 則藻體薄, 但如過晚, 就有大量

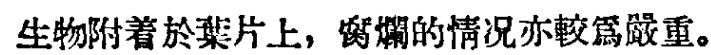

（二）收穫方法: 在海底自然繁殖或探抢子 投石的海帶的收稜可以由酒水員在海底用手或䍊 刀收割, 也可以用四角小鐵錯抛到海底拒拉, 把海 帮從柄部或固定器部拉断, 海帶自然就漂浮水面。 浮架上培養的海帶在收穕時漸繩一齊折到陸地。

（三）生產量: 我國海帶的養殖是在解放後 戈有計劃地走向企業化的道路的, 因此生産量還

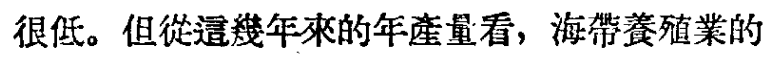
進展是非常迅速的。1949 年剛解放後, 山東沿海 海底人工繁殖的海帶生長的面積逼不到數百平方 米, 1952 年發展到 1 禹本方米, 1953 年增加到 2 萬 6 千餘平方米, 在座量方面, 1952 年山東沿 海收制了 13 萬厅鮮海帶, 1953 年的生產量增加 到 47 萬斤。1952 年旅大區的産量篇山東的雨倍 多, 1953 年的産量估計亦比例增加。

海帶單位面積生座量的估計没有像酦作物那 察淮磪，特别是任海底的自然繁殖。在大連的幾 倜自然繁殖區中, 产量俥高的海區, 每本方米的
乾品座量約篇 3 术厅，如以每弶海底只有一牛生

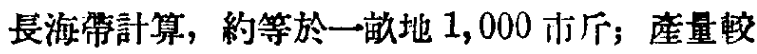
差的地區, 平方米的座量只有 1 标沂, 每敵地的

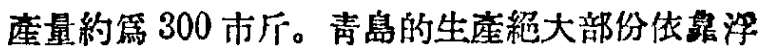
架的食殖, 單位面積的生産量的估訪是比较沙確

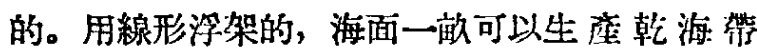
427 斤; 用梯形浮架的一弶可以生產乾品 960 市 斤.

從表面上看，每嘼海區在不加以人工改造的

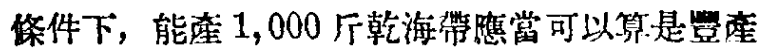
了，但是海帶的產量是全植物體的重量，不像大 米、小麥或棉花的產量只是植物體的一部份而已， 所以海帶的可能尘量還應當大幾倍。1953年在旅 大䓹殖場的一個試驗浮架上，60平方米的泊皘就 生産了 3,000 斤鮮海帶，折合乾品世有 450 斤。

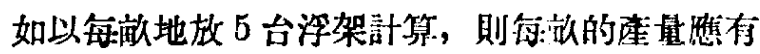
2,250 斤。如果進一步改善餈殖技術蓝進行人工

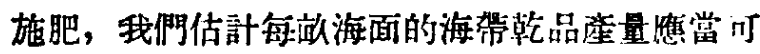
以澾到 3,000 斤。

\section{三 存在的問題}

（一）掌握海帶的生活條件和告長與發育規 律的問題:

目前海帶工作者還沟有掌握海帶的生活條件 和生長與發有的規律。我椚和山束水產養殖場管 經做了一些賽驗，得到了幾项初步的絬果。例如 海帶配子體階段在弱光或高温就不能發育第子第子 體; 但配子體的抵抗力却很强, 在 $31-32^{\circ} \mathrm{C}$ 骨湿 及惡劣環境還能維持生活; 相反的, 幼阤子-觶的 抵抗力较差, 到不了 $26-27^{\circ} \mathrm{C}$ 就死亡; 另外在确

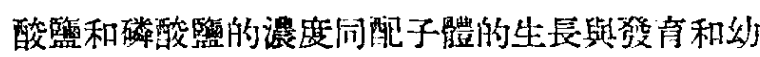
阤子體的生長的關係上也有些認畿。但這些問題 的研究還很表面、片面，離開我僩的要求還甚: 遠。目前很多有關於生活保件和生長規律的問題 分未能得到科學上的答案, 因而一些啬殖上的困 難至今未能解决。

（1）孢子敬的成熟: 在䓹殖操作上, 海帶 的探孢子是一個基本的工作，這项工作的大前提 就是孢子繁的成䓡; 因此掌握孢子震的發生和成 熟的規律是海帶養殖業的一個重要問題。根據高 等植物的階段發育的理論, 我們可以推測海帶孢 子體必須獲得了某些環境因子, 特别是温度和光 


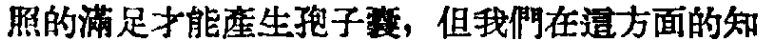
識目前還極贫乏。

根幏我們的經驗，靑島一些地區的海帶到了 四月間就有一部份開始座生孢子垡, 這些海帶都 是生長在浮架的最上畨, 因而也是接受最多的光 照的; 孢子裂的產生都是從棐片的媔端開始的。 很明顛的，這些產生孢子校的部份已經獲得了温 度和光照的滿足。但這種現貌亚不普掘，而且在 1953 年四、五月間, 雖然青島的海帶已經有訣 多産生了孢子暴, 但在大漸, 到了五、六月間,

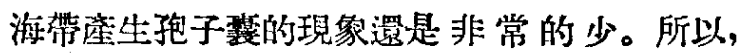
單純用温度和光照來解釋這種現象還是不能令人 滿意。

在青島地區，到了夏天，孢子管的座生就停 止了; 過夏以後, 到了十月間, 所有的海帶普邀

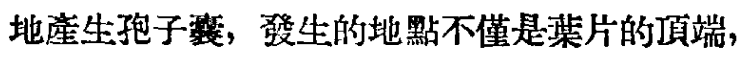
而是在整個棐片上。孢子放散後 $1-2$ 個月, 海尖 就開始衰老阿死亡; 因此，在青島基本上就没有 二年生海帶。在日本北海道原產地和旅大地區, 海帶在第二年秋天也普遍地發生孢子䓯, 但一般 均在棐片的項端，到了第三年的秋天，孢子薪才普 遍地在整個葉面發生，然後才寒老死亡。我們對 於海帶的齐旺是能够改變第多年生, 最少也能够 像原產地和旅大地匰一樣, 可以保持二年生的習 性，能够從第二年的秋天繼續生長到第三年，因 第第二年生的海帶生活力較强，藻體亦較䍃宽 厚，因面险品價值亦較高。但是，在我們沒有掌 握孢子整發生和成熟規律以前, 我們還無從抑制 孢子慗们產生或者加速共成熟。

（2）幼莎的發生：從孢子附着在生長基留到 肉哏能看出的幼落的出現, 是海帶養殖上一個重 要的關鍵階段。這期間踓然很短，只有一個多月， 但在生活生上，海帶却渡過了孢子萌發成第配子 體, 配子體發育產生卯和精子以及卯受精後發展 第子㐌子體這樣三個階段。在理論上，這三個階段 應當各有其特殊性，對於環境因子亦各有其特殊 的要求，但目前我們所能了解的還是太少，還沒 有控制各個階段的生長和發育的能力。

經驗告訴我們，在晚秋初冬期間的山東海遌， 海帶配子體管要一定强度的陽光才能發育篇子色子 體, 因此孢子體發生早的, 都是接近水面的。孢 子體如不能發生出來, 時常是因篇浮架上生長了
質多附着物遮着光線的緗故。但也有同一來源的 孢子在一個海區正常橅生幼笛; 而在光線很充足 但無機養份較蘑的另一個海區, 却長不出孢子體

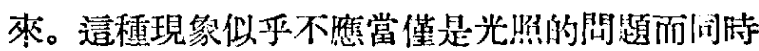
也是篦䓹的開題。在另外一些貫驗, 我們义證明 了海带配子體在 $20^{\circ} \mathrm{C}$ 以上就不能正常發育篦孢 子體。

根㨜上而所提的事筫，我們認戨到：海帶㭃 苗的發生是通過了許多因子，包括温度、光然和鉒 份的複雜錯綜的關係的, 而不是單純菒一個团子， 如光照的問題。我們還認識到, 如要保登海帶配 子體能够勝利地發育第阤子體, 就必須滿足它的 各個發育階段的要求。但是我們現在所能掌据的 造方泊的知識還很少。

(3)藻體的白爛: 單純從病態的表面現象看, 海帶的白爛很儌是因第光綫過强所致。海帶在日 本北海道原喾地的最適宜生長水居在 乾潮下 10 米以下，但在我國食殖的水居却 篇 乾潮下 1-3 米; 從這一點看, 强光引起海帶的白爛似乎是正 確的解釋, 但是有些海區, 海帶在 3 月間就開始 白爛，5-6 月間最篇䇴重; 而同一時間，在另外 一些海水透明度相似的海區，海帶的白爛現象甚 篇輕微, 或者完全没有。以前, 山東水虐䓹殖場 認第白爛是“强光病”，因此，在渡夏期，管經將 海帶沉人 10 米以下的海底, 但白爛的現像亚不因

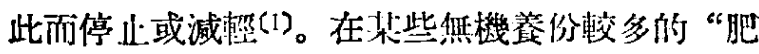

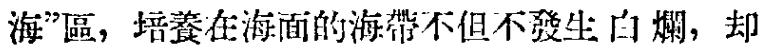
反而長得特别强让。通過了許多具體的例子，海 帶工作者現在都認識到，不能用單純的光䋐强抲 的影響去解釋這種病態現象, 而必須從環境因子 棕合的錯綜關係去看，才能够得到正確的答案。

（二）選種育種的問題:

海帶的人工姜殖歷史太短，選種和育種遺末 得到應有的重視, 現在各地所培養的海帶是否有 不同品種的存在還不能肯定，因此，不管游洋環

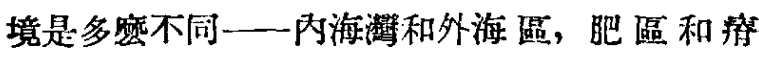
區, 都千篇一律地應用同樣特性的海帶。

提我們觀繁，在大連生長的和在青島生镸的 海帶是有些相當顯著的差異的, 踓然青島的海帶 也是從大逨移種過來的。但這些區别是代表品種

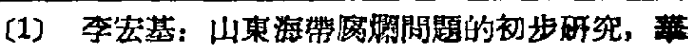
東水座, $1952(11-12), 57-66$ 。
5月號

科學通報 
上的不同或者僅是因第晎境的不同而致，由於缺 少經驗，還不能下結諭。我們去年會做了一些大 連的和青島的海帶的雜交試驗, 没有成功。今年 重複了同樣的試驗，初步的結果還好，但孢子體 還很幼，是否能够得到預期的結果份難預測。局 了獲得一個抗温力較强的品種, 去年我們會經用 海帶的配子體和產於㽬建沿海的一種昆不類植物 我掌荣 (Ecklonia Kurome Okam.) 的配子體雜 交, 結果也尖敗了。我們的目的, 是乔望通過海 帶的選種和育種能够獲得一些適合於我國各個地 區的特殊的海洋環境的品種, 但目前還存在着許 多需要克服的困難。

（三）外海䓹殖問題:

目前我國海帶的人工奉殖一般都在海灌內， 特别是在城沛污水經常流出的海區進行。這種海 區不但風浪較小，可以應用浮架式的養殖方法， 而且無機養份的含量較高, 海帶生長較䉆迅速, 因此逼種海區䅘篇“肥區”。相反的，一般的外海 䠄不但風浪較大，而且所舍無機養份也較少，海 帶生長不良，故稱篇“瘦區”。我國北部沿海絕大 部份虽於痊區; 如果我們不能使海帶在這種海區 生長良好, 我國海帶菨殖業的前途是 不能樂 觀 的，生産量是不能滿足人民需要的。因此，如何

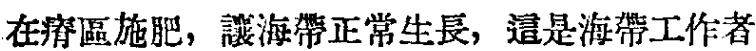
當前的一個主要任務。我們和中央水座賽驗所的 同志們已䍃開始分别應用不同方法去解决遣個問 題。

（四）有害生物的閏題:

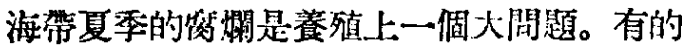

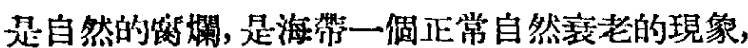
只限於項端艺成部。有的是因瞩環境不適合而引 起的生理病現像，具體表現篇“白䑌病”。有的是 因篬其他生物的直接篇害而引起的病㕩現象，一

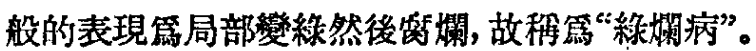
據我們的觀察，這種病多數是由於生物的機械傷 害以及細菌侵入所致。海帶藻體在夏季生活力很 低，細胞分裂基本停止，如被生物咬偤或其他原 因局部細胞死亡，很不容易在短期間內滧合。在 䢧種情况下, 細菌很容易由傷口進入而引起傗爛。

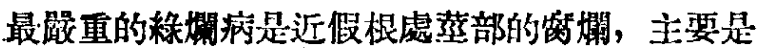

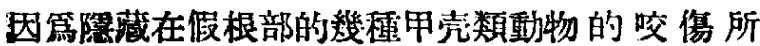

致。1953年青島渡夏的種游管因授生了䢙種疙大 部份棐片斷掉而遗失。根㨡我們初少的試驗, 用 666 和除蟲菊混合剂的水溶液浸泡假根部 1-2分 鐘, 有殺死這些有害生物的能力, 樂品處理後, 病害有減輕的情况。

海帶的敵人還有澵多附着於浮架上或者海帶 藻體上的生物。在秋季海乖浮架上的水零及其他 藻類如長得太長, 會影響到海帶幼苗的發生, 促 重的時候，海帶幻落大部份長不出來。在夏季，

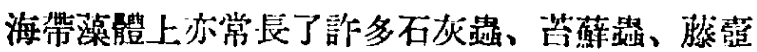
以及其他動物，多的時候不但影響到海帶品犋， 而且也阻止了孢子数的發生。

還些有害生物，不論是否引起海帶的䈍爛， 對於海帶的養殖業都是很大的威骨。因此, 如何 防治這些有害生物的生长，也是目前亟待解决的 問題。

（五）提高單位面積生尘量的問題:

逜問題在目前雖然還不是一個主要的問題, 但如果單位面皘産量能再提高, 成本能再減低, 就有可能將海帶的養殖發展第翠衆性的事業, 這 對於擴大海帶的食殖面積就可以起很大的作用。

我們認篇海帶的大量生座主要將依靠浮架式 的食殖，因篇這種方法較黨科學化，人工控制的 成份較高，比較接近於费同的耕程，因此，浮梨

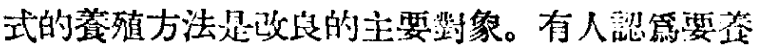
育揵全的種苗，分散是絕對必要的。在一定的條

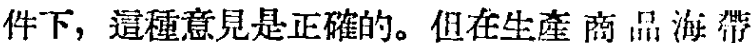
時, 如過份的强調分散, 就會影響到生產量。在 自然的條件下，海帶的生長是相當的密 集䔦 生 的, 但在 1953 年以前的浮架茶殖, 每一點只炏一 二棵㭃草，似乎不符合於自然的生長規律。因

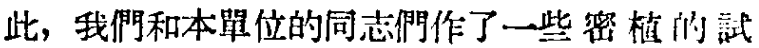
驗, 初步的結果證明了密植可以增座。當然, 如

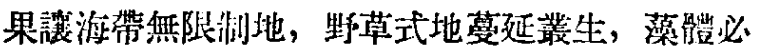
然較薄較小，颜品價値也必然較低。科學的密植

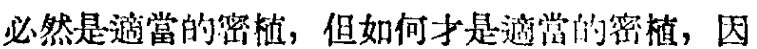
地而買, 需泟海帶工作者根據就地的読况, 通過 具體的試驗才能决定。

密植不過是很多提高單位面積生産方法之 一。這方面的工作做得太少, 應賞是旅洮工作中 的一個重要方向。 